\title{
An FEA based study of thermal behaviour of ultrasonically welded phosphor bronze sheets
}

\author{
Bharat Sanga ${ }^{1}$, Reeta Wattal ${ }^{2}$ and D.S. Nagesh ${ }^{3}$ \\ ${ }^{1}$ Department of Mechanical Engineering, Guru Nanak Dev Institute of Technology, Delhi 110089, India \\ Phone: +919013310266 \\ 2,3 Department of Mechanical Engineering, Delhi Technological University, Delhi 110042, India
}

\begin{abstract}
The ultrasonic joining of phosphor bronze sheets is analyzed using a 3-D finite element model for the study and prediction of the thermal profiles at the weld interface. The heat fluxes are calculated and assigned as boundary conditions during the thermal simulation. The forecast of temperature is done under various welding conditions. The maximum temperature obtained by transient simulation at the weld interface is $366.74^{\circ} \mathrm{C}$. The continuous reduction in the temperature is observed towards the extremes of the weld metal. The sonotrode and the anvil achieve a lower temperature in comparison to the weld interface. The effect of clamping force and bonding ratio on the interface temperature is observed as positive. The model is validated with an error of $1.576 \%$ between the observed and predicted temperature results and a correlation coefficient 0.96 is established between the simulated temperature results and the weld strength. Sufficiently strong joints were obtained at the optimum welding conditions with $74 \%$ joint efficiency. It is evident that the interface temperature has a strong linear relationship with joint strength and is a major deciding factor for achieving strong joints.
\end{abstract}

\author{
ARTICLE HISTORY \\ Received: $24^{\text {th }}$ July 2020 \\ Revised: $11^{\text {th }}$ Oct 2020 \\ Accepted: 24th Jan 2021

\section{KEYWORDS} \\ Ultrasonic welding; \\ finite element analysis; \\ simulation; \\ SimScale; \\ heat flux; \\ temperature profile; \\ plastic deformation; \\ friction; \\ thermocouple
}

\section{INTRODUCTION}

The current industrial need of producing innovative and sustainable products demands for robust and compact design. The need can be accomplished by the use of light-weight materials fulfilling specific product design requirements. Typically, aluminum and copper based alloys are extensively chosen for manufacturing parts of Battery Electric Vehicles (BEV) such as electrical contacts, terminals, current collectors, and bus bars owing to their excellent strength and spectacular electrical and thermal properties [1] . Some commonly used joining techniques such as resistance welding, micro-TIG welding and laser welding pose electrical, thermal, metallurgical, and mechanical challenges to the joint characteristics [2]. Incessant efforts are being made to evolve better techniques for thin sheet joining. Conventional joining methods are modified to suit the needs of heterogeneous tiny joints. Resistance micro-welding, laser droplet joining, duothermal soldering process, and precision miniaturized droplet deposition technique are some of the newly evolved techniques [3-6]. These techniques still need standardization due to diverse material characteristics. Ultrasonic welding (USW) is an emerging technique for manufacturing these parts owing to its superfast joining time, excellent weld quality, and capability to join dissimilar materials with the least power consumption. It is a friction oriented joining method that utilizes acoustic energy to plastically deform the metal and bringing the nascent metal surfaces in close contact so as to form a strong metallic bond [7]. Fairly seen simple from outside, the actual mechanism of joint formation in USW is quite complex [8]. In fact, an accurate and well-established theory related to the joint mechanism of USW is yet to be developed [9]. There is a need to regulate the operating procedure to make this technique a commonly utilized popular joining method.

Process optimization and microstructural evaluation of USW are some of the fields explored by a number of researchers [10-13] for a variety of metal combinations. Elangovan et al. [10] joined dissimilar 0.2 and $0.3 \mathrm{~mm}$ thick sheets of $\mathrm{Cu}$ and brass using USW. Welding parameters were optimized to maximize weld strength by interfacing the Response Surface Method (RSM) with the Genetic Algorithm (GA). Similarly, thin sheets of aluminum and steel were successfully joined and parameters were optimized using Artificial Neural Network (ANN) in association with GA by Zhao Dewang et al. [11]. During their observation, weld time was found to be the most important parameter, however, vibration amplitude and clamping force did not affect significantly. A dissimilar weld between aluminum and copper with aluminum alloy particle interlayer was created and the effect of weld energy on weld strength was investigated and substantiated with the microstructural evolution by Ni Zenglei et al. [12]. The weld strength increased with increasing energy and no traces of IMCs were observed. The particle interlayer also affected the weld strength to a great extent. Copper wire joints find numerous applications in electrical and electronics products. Mohan Raj et al. [13] investigated the joining of copper wire with the copper substrate. Their work involved parametric optimization, microstructural evaluation, and numerical modelling. The FEM analysis revealed that thermal stresses developed at the interface. FEM based models are simulated for estimating mechanical and thermal impacts of operating conditions of ultrasonically 
welded joints [14-21]. Zhong et al. [14] performed an experimental study and modelling of the ultrasonic consolidation process of dissimilar $\mathrm{Ti}$ and $\mathrm{Al}$ alloys. The highest temperature was obtained at the common surfaces of foil-sonotrode and foil-substrate. They also observed that the oscillator amplitude had more effect on the interfacial temperature than the consolidation pressure. Besides metals, modelling of thermo-plastic was performed using ANSYS software and the results were authenticated with the experimentally obtained data [15]. A detailed study of different similar and dissimilar metal ultrasonic joints was done by DeVries [16]. The effect of significant process parameters, microstructural transformation, and evaluation of HAZ in the weld zone and simulation of 3-D CAD model were the primary objectives of his work. The heat developed at the weld interface was estimated and the model was utilized to predict the interfacial temperature. Similar work was done by Elangovan et al. [17, 18]. The finite element based model was presented to simulate the actual working conditions of the ultrasonic welding for predicting the temperature distribution at the weld interface as well as the stress distribution in the sonotrode and the joint. The simulated results were found in good concurrence with those acquired experimentally. Chen and Zhang [19] constructed and simulated the 3-D model of USW of dissimilar automotive alloy and found that the temperature distribution was not uniform at the knurled surface of the sonotrode tip. The amount of heat produced due to plastic deformation was almost one-fourth of the total heat produced at the interface and the highest temperature was located at the weld interface. Aluminum alloy AA 6011 was joined separately by magnesium alloy AZ31 and low carbon steel DC04 by Jedrasiak et al.[20]usingUSW. The heat input during welding was evaluated using thermocouple data and some other evidence. The thermal histories were utilized to predict the thickness of the intermetallic compound. A 3-D finite element model of the thermal field was applied for temperature prediction at the weld interface. The same author also simulated the heat generation in USW using finite element analysis [21]. A single cycle oscillation deformation model was employed for calculating the heat generation rate sporadically. A continuous thermal model was capable to predict the temperature field.

It is clear from the review of the literature that modelling of the thermal field plays an important role in the prediction of the temperature profile at the weld interface. The response characteristics of the USW process can be forecast, and the corresponding data can be utilized optimally by the industry. Keeping these implications in mind, the current work is focused on the development and simulation of a 3-D finite element model of thin sheets of phosphor bronze joined by USW. The CAD model was employed to have a close inspection into the thermal phenomenon leading to the joining process and consequent assessment of its impact. This work involves the following objectives: (i) measurement of interface temperature and the strength of the weld joint (ii) calculation of heat generation at the weld interface (iii) development of a CAD model and its analysis using FEA technique to predict the temperature at different zones of the interface and (iv) establish a correlation between the interface temperature and the strength of the joint.

\section{METHODS AND MATERIALS}

\section{Equipment and Material Layout}

In the present study, the weld coupons of phosphor bronze sheets (UNS C51100) having size $100 \mathrm{~mm} \times 25 \mathrm{~mm} \times 0.36$ $\mathrm{mm}$ have been prepared with a $25 \mathrm{~mm}$ overlap. A lateral drive Telesonic $₫$ ultrasonic welding machine $(20 \mathrm{kHz}, 3 \mathrm{~kW})$ with knurled horn tip of size $13 \mathrm{~mm}$ x $10 \mathrm{~mm}$ was employed for performing the experimental work. The experiments and simulation are performed considering three parameters, weld time $\left(\mathrm{W}_{\mathrm{t}}\right)$ clamping force $\left(\mathrm{F}_{\mathrm{c}}\right)$, and vibration amplitude of the sonotrode $\left(\mathrm{V}_{\mathrm{a}}\right)$. The selection of parameters is based on the literature survey and the preliminary experiments conducted to evaluate the range of parameters. The value of each parameter was varied at three levels as shown in Table 1.

Table 1. Welding parameters and their levels

\begin{tabular}{cccccc}
\hline Factor & Unit & Symbol & Level 1 & Level 2 & Level 3 \\
\hline Weld Time & $\mathrm{Sec}$ & $\mathrm{W}_{\mathrm{t}}$ & 0.50 & 0.85 & 1.20 \\
Clamping Force & $\mathrm{N}$ & $\mathrm{F}_{\mathrm{c}}$ & 1100 & 1650 & 2200 \\
Vibration Amplitude & $\mu \mathrm{m}$ & $\mathrm{V}_{\mathrm{a}}$ & 28.0 & 31.5 & 35.0 \\
\hline
\end{tabular}

The ultimate tensile-shear load of the weld joint and the temperature at the interface were measured to evaluate the performance of the ultrasonic welded joint. The experiments were executed as per the Box-Behnken design owing to its advantage of requiring a lesser number of experiments. Each weld parameter was selected at 3 levels for conducting 15 randomized experiments each with 6 replicates. Before making the joints, the specimens were properly swabbed with acetone and dried to remove the oils and grease from the contacting surfaces to ensure close contact between them. The tensile-shear load of the weld coupons was tested on Tinius Olsen (Model: H50KS) computerized universal testing machine (UTM) with constant crosshead speed at $1 \mathrm{~mm} / \mathrm{min}$. The schematic diagram and the actually welded coupons are shown in Figure 1. 

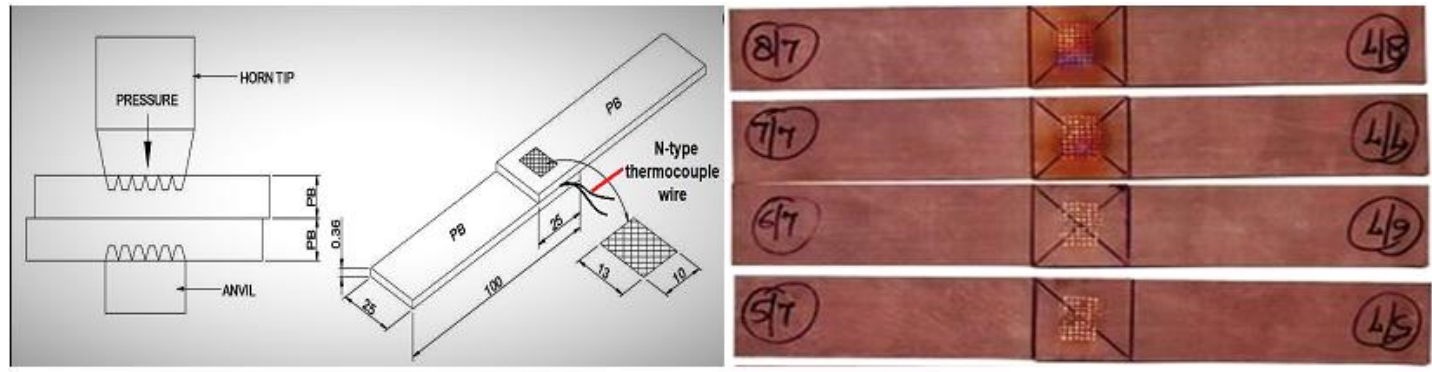

Figure 1. Schematic of weld coupon with N-type thermocouple wire attached at the middle of the overlapped area and experimental weld specimens

The real-time interface temperature was measured using a Data Acquisition System (DAQ) during the welding. Data Translation ${ }^{\circledR}$ make DT9828, 8 channel isolated thermocouple DAQ module having a sampling rate of $600 \mathrm{~Hz}$ and accuracy of $0.09^{\circ} \mathrm{C}$ was employed for the processing of temperature data. The temperature measuring sensor used for this work was $0.20 \mathrm{~mm}$ diameter sacrificial N-type (Nicrosil-Nisil) thermocouple wire which has a working range between $270^{\circ} \mathrm{C}$ and $+1300^{\circ} \mathrm{C}$. It was placed at the centre of the overlapped portions of the weld coupon touching the interface, considering it as the hottest point during the welding. The $\mathrm{N}$-type thermocouple has a very high sensitivity index $(39 \mu \mathrm{V}$ $/{ }^{\circ} \mathrm{C}$ at $900^{\circ} \mathrm{C}$ ) and thermo-electrical stability as compared to other thermocouples. Further, the DAQ module was interfaced with the QuickDAQ software to process the real-time interface temperature value. The QuickDAQ software has the functionality of converting the electrical signals generated by the thermocouple to the temperature values and showing them in the graphical form. The whole system of temperature measurement and processing can be shown through a block diagram as shown in Figure 2.

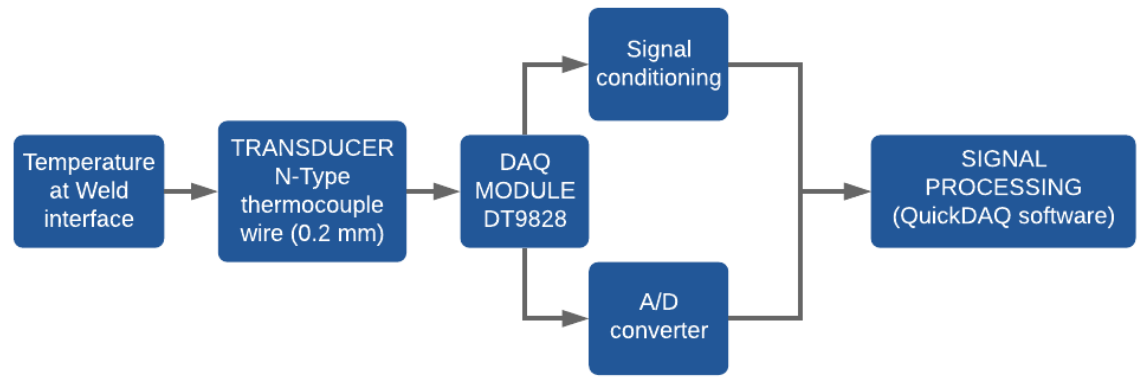

Figure 2. Block diagram of DAQ system

\section{THERMAL ANALYSIS OF ULTRASONIC WELDING}

The mechanism of joint formation in USW makes it a complicated joining process due to the application of remarkably low-amplitude and high-frequency vibrations on a small region for a very short period. The heat produced at the joining surfaces is not ample to melt the metal but again is sufficient enough to produce a strong joint in the cold condition. The contaminants and the surfacial asperities initially prevent the weld metals to make intimate contact. But at the same time, the periodic shear stresses developed due to the vibration of the sonotrode and the pressure exerted on it produce sufficient instantaneous heat. It eventually softens the metal, disperses the contaminants and thus, a sound metallic joint is formed. The factors responsible for the rise of a significant amount of heat delivered at the weld zone during ultrasonic welding are material deformation, friction, and vibration [22]. Initially, the effect of friction is observed between the sonotrode tip and the upper sheet for negligible time, hence, this may be considered insignificant [16].

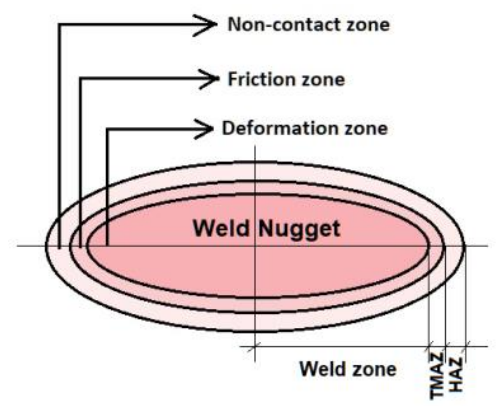

Figure 3. Weld nugget demarcation into different zones 
In the meantime, as the welding process proceeds, the heat due to deformation and friction between the sheets rises significantly and the formation of small micro-welds begins. Very soon, these micro-welds expand and propagate on a larger surface. The form of the micro-welds then converts into macro-welds or the weld nuggets. Figure 3 shows the different zones of the affected area.

The zone where deformation of the weld metal takes place and formation of the micro-welds starts is known as the 'deformation zone'. The size of this zone increases continuously and may reach up to the size of the sonotrode tip depending upon the penetration of the sonotrode teeth. The effect of heat and stress is observed in this zone. This zone is surrounded by the 'friction zone' whose size is slightly more than the deformation zone due to the vibrating sonotrode. Although the weld metal gets deformed in this zone, the formation of micro-welds does not take place due to insufficient heat generation. This zone is also known as the thermo-mechanically affected zone (TMAZ). The deformation of metal and the friction between the faying surfaces are the primary factors of heat generation in the 'deformation zone' and the 'friction zone' respectively. Lastly, the heat-affected zone (HAZ) is found adjacent to TMAZ which is characterized by the heat only [23]. This work involves the well-approximated estimation of the heat generation due to the deformation of the metal and friction between the mating surfaces. Based on these estimations, a thermal model has been prepared and utilized to calculate the size of the weld zone, TMAZ, and HAZ.

\section{Measurement of Weld Area}

The estimation of the actual weld area is essential for the calculation of heat flux at the interface. The weld joint formed in the case of USW contains a number of small macro-welds or nuggets. The net weld area is the sum of all the nuggets. It was observed that the weld coupons stick on to a relatively smaller portion of the interface that makes it difficult to estimate the actual weld area. The actual weld area is the result of different combinations of parameters. In the case of knurled sonotrode tip and thin weld metal sheets, the depth by which the teeth on sonotrode tip get penetrated onto the upper sheet vary with parameter combination. Secondly, unlike resistance spot welding, the weld area is the sum of the areas of a number of micro-welds which appear on the separated surfaces as macro-welds or weld spots. The metal under a tooth gets deformed and spreads in a larger surface, but as observed, it does not join strongly with its countersurface surrounding the teeth. Whereas, the interface below a tooth gets attached so strongly that while detaching it peels off the surface of another sheet.

Two different methods have been employed to enhance the accuracy of the work due to the irregular shape and size of the weld spots. In the first method, the cross-sectional area of one sonotrode tooth was calculated by enlarging the tooth impressions on the interface using a profile projector and multiplied by the number of weld spots present at the weld interface. In the second method, the bond impressions on the magnified interface were summed up using ImageJ software (Version 1.52 a). Both sides of the interface of each weld coupon were taken into consideration to improve the precision of the results. This way, six areas were measured at each run of the design matrix. The mean value of the two areas was taken as the final weld area.

\section{Heat Flux Calculation}

The basic model for the calculation of heat flux is based upon the fact that the joint is formed as a result of heat produced due to (i) the shear deformation of the weld metal below the sonotrode tip and (ii) the friction between the contacting surfaces of the weld metal. The shear deformation of the weld metal is subjected to (i) the normal compressive stresses due to clamping force and (ii) the shear stresses due to ultrasonic vibrations. The combined effect of these two stresses brings the material under plastic deformation resulting in the generation of excessive heat which raises the temperature of the material instantly. As the deformation takes place under one normal and one shear stress, the failure of the material may be considered to follow Tresca's failure criterion which states that failure occurs when the maximum shear stress reaches its critical value that is the yield stress in a normal tensile test. Using this concept, the value of shear stress which is responsible for the deformation may be calculated as:

$$
\mathrm{f}_{\max }=\frac{\sigma_{1}-\sigma_{2}}{2}=\sqrt{\left(\frac{\sigma_{\mathrm{N}}}{2}\right)^{2}+\left(\mathrm{f}_{\mathrm{s}}\right)^{2}}
$$

Where, $\mathrm{f}_{\max }$ is the maximum shear stress, $\sigma_{1}$ and $\sigma_{2}$ are principal stresses, $\sigma_{\mathrm{N}}$ is the normal stress due to pressure and $\mathrm{f}_{\mathrm{s}}$ is the shear stress responsible for deformation. So, according to Tresca's condition, if ' $\mathrm{Y}$ ' is the yield stress of the material during a normal tensile test, Eq. (1) can be formulated as:

$$
\frac{Y}{2}=\sqrt{\left(\frac{\sigma_{\mathrm{N}}}{2}\right)^{2}+\left(\mathrm{f}_{\mathrm{s}}\right)^{2}}
$$

So, value of shear stress,

$$
\mathrm{f}_{\mathrm{S}}=\sqrt{\left(\frac{Y}{2}\right)^{2}-\left(\frac{\sigma_{\mathrm{N}}}{2}\right)^{2}}
$$


Or

$$
\mathrm{f}_{\mathrm{s}}=\sqrt{\left(\frac{Y_{\mathrm{t}}}{2}\right)^{2}-\left(\frac{\mathrm{F}_{\mathrm{c}} / A_{\mathrm{d}}}{2}\right)^{2}}
$$

Where, $Y_{\mathrm{t}}$ is the temperature-dependent yield stress, $\mathrm{F}_{\mathrm{c}}$ is the clamping force and $A_{\mathrm{d}}$ is the area of the deformation zone. The power dissipated $(\mathrm{P})$ in the deformation zone produces heat flux at the interface which is a function of the average sonotrode velocity $\left(\mathrm{V}_{\text {avg }}\right)$ and the weld force $\left(\mathrm{F}_{\mathrm{w}}\right)$. Therefore, the heat flux due to deformation $\left(\mathrm{H}_{\mathrm{d}}\right) \mathrm{in} \mathrm{W/ \textrm {m } ^ { 2 }}$ can be shown as Eq. (5):

$$
H_{d}=\frac{P}{A_{d}}=\frac{F_{W} \times V_{\text {avg }}}{A_{d}}
$$

Ideally, for thin sheets and flat sonotrode tip, the area of deformation can be considered equal to the sonotrode area $\left(A_{s}\right)$ since the entire area beneath sonotrode tip gets deformed. Now, Eq. (5) can be written as:

$$
\begin{gathered}
H_{d}=\frac{f_{s} \times A_{w} \times V_{\text {avg }}}{A_{s}} \\
H_{d}=\left(A_{w} / A_{s}\right) \times V_{\text {avg }} \times f_{s}
\end{gathered}
$$

Substituting the shear stress, $f_{s}$ in Eq. (6) from Eq. (4), we can write Eq. (7) as

$$
\begin{gathered}
H_{d}=\left(A_{w} / A_{s}\right) \times V_{a v g} \times \sqrt{\left(\frac{Y_{t}}{2}\right)^{2}-\left(\frac{F_{c} / A_{s}}{2}\right)^{2}} \\
H_{d}=\left(\frac{\beta}{2}\right) \times V_{a v g} \times \sqrt{\left(Y_{t}\right)^{2}-\left(F_{c} / A_{s}\right)^{2}}
\end{gathered}
$$

The average velocity of the sonotrode in Eq. (8) can be calculated by $V_{a v g}=4 \times V_{a} \times V_{f}$ where $V_{a}$ and $V_{f}$ are the amplitude and frequency of the ultrasonic vibrations. ' $\beta$ ' is the bonding ratio which signifies the extent of the area under the sonotrode tip that is transformed into weld zone. Its value is indicative of the effectiveness of the process which itself is the resultant of many factors and one of the most important factors is the heat generated at the interface. The ideal value of ' $\beta$ ' should be 1 when the whole of the area under sonotrode tip is engrossed with the micro-welds but due to the presence of oxide, asperities, and other contaminants, some portion remains unbounded.

The temperature-dependent yield strength $\left(\mathrm{Y}_{\mathrm{t}}\right)$ of phosphor bronze is assumed to equal to its yield strength in normal conditions. Some alloys such as phosphor bronze do not lose an appreciable amount of their strength at a higher temperature until $350^{\circ} \mathrm{C}[24]$ and it was observed during experimentation that the maximum average interface temperature where deformation takes place did not exceed $354.7^{\circ} \mathrm{C}$. The calculation of heat flux due to deformation of weld metal according to Eq. (8) has been done for weld coupon having the lowest bonding ratio $(\beta)$ of 0.26 , clamping force of 1100 $\mathrm{N}$, weld time of $0.85 \mathrm{sec}$, sonotrode amplitude of $28 \mu \mathrm{m}$ and is shown below:

$$
H_{d}=\left(\frac{0.26}{2}\right) \times 2.24 \times \sqrt{\left(295 \times 10^{6}\right)^{2}-\left(1100 /\left(130 \times 10^{-6}\right)\right)^{2}}=85.87 \times 10^{6} \mathrm{~W} / \mathrm{m}^{2}
$$

The heat flux due to friction $\left(\mathrm{H}_{\mathrm{f}}\right)$ between the mating surfaces of the workpiece depends upon the dynamic coefficient of friction between the surfaces $\left(\mu_{\mathrm{k}}\right)$, the clamping force $\left(\mathrm{F}_{\mathrm{c}}\right)$, and the average sonotrode velocity $\left(\mathrm{V}_{\mathrm{avg}}\right)$. The value of $\mu_{\mathrm{k}}$ is taken as 0.85 for phosphor bronze sheets. Heat flux due to friction may be calculated using Eq. (9).

$$
H_{\mathrm{f}}=\frac{\mu_{\mathrm{k}} \times \mathrm{F}_{\mathrm{c}} \times \mathrm{V}_{\mathrm{avg}}}{\mathrm{A}_{\mathrm{s}}}
$$

Therefore,

$$
\mathrm{H}_{\mathrm{f}}=\frac{0.85 \times 1100 \times 2.24}{130 \times 10^{-6}}=16.11 \times 10^{6} \mathrm{~W} / \mathrm{m}^{2}
$$

The total heat flux $\mathrm{H}$ is the sum of heat flux due to deformation $\left(\mathrm{H}_{\mathrm{d}}\right)$ and heat flux due to friction $\left(\mathrm{H}_{\mathrm{f}}\right)$. Therefore, $\mathrm{H}$ $=85.87 \times 10^{6} \mathrm{~W} / \mathrm{m}^{2}+16.11 \times 10^{6} \mathrm{~W} / \mathrm{m}^{2}=101.98 \times 10^{6} \mathrm{~W} / \mathrm{m}^{2}$. A similar calculation was performed for calculating the heat fluxes at each run and the heat flux value has been imposed as one of the boundary conditions during simulation of the CAD model of the USW of phosphor bronze sheets. 


\section{Finite Element Analysis (FEA)}

The CAD model of the ultrasonic welded joint between phosphor bronze sheets was prepared and simulated for thermal analysis using SimScale Workbench 2.0 software (SimScale GmBH). SimScale Workbench is an open-source cloud-based CAE computing environment providing up to 96 core computing capability for simulation [25]. The geometry, mesh, and the working boundary conditions of the FE model are shown in Figure 4. The proposed model can be used for simulation of USW of similar as well as dissimilar materials. The CAD model, which is actually a replica of USW process, is comprised of three parts connected closely with each other - the weld metals, the anvil and the sonotrode. Accordingly, the model was associated with three materials: the weld material phosphor bronze (UNS C51100), sonotrode material Ti alloy, and anvil material tool steel. The complete assembly of sonotrode was not included in the model, as the thermal conductivity of the sonotrode material is very low as compared to the weld metal and the processing time in USW is very small. Hence, only the sonotrode tip is included in the analysis. The meshing of the model was kept to the finest with tetrahedral mesh element graded from coarse to fine, with the finest mesh at the central part. The current model used 577856 elements with 152203 nodes and 4164 edges as shown in Figure 4. This meshing scheme was adopted to improve the computational accuracy of the analysis and to reduce the hourglass effect [26].

Along with that, the physical, mechanical and thermal properties of the materials such as melting point, Young's modulus, yield strength, Poisson's ratio, thermal conductivity, etc. are included in the model [27] and are shown in Table 2. All the components of the FE model are presumed equivalent to the actual physically assembled USW process in their orientation and physical attribute. The anvil, a stationary part of the ultrasonic metal welding machine is made fixed in the FE model also by restricting all of its degrees of freedom. The clamping pressure plays an important role in the formation of the weld joint in USW. So, it becomes imperative to give due consideration to its effect on different contact areas in the FE model. The portions of the weld coupons which are away from the thin weld zone and are surrounded by air may be considered as insulated due to the low convective coefficient of air and short weld time. Similarly, it was practically observed that the portions of the overlapped weld coupons away from the weld zone get slightly separated due to less impact of clamping pressure, and the air gets entrapped between the sheets. Hence, they are also treated as insulated boundaries. The contacting parts must have a large thermal contact conductance being highly conductive soft metals with clean and flat faying surfaces. Pressure as well as vibratory motion also contribute to enhance its value [28]. So, the value of thermal contact conductance was taken as $10^{4} \mathrm{Wm}^{-1} \mathrm{C}^{-1}$ for the weld interface and the interface between the sonotrode tip and the upper weld coupon [20].

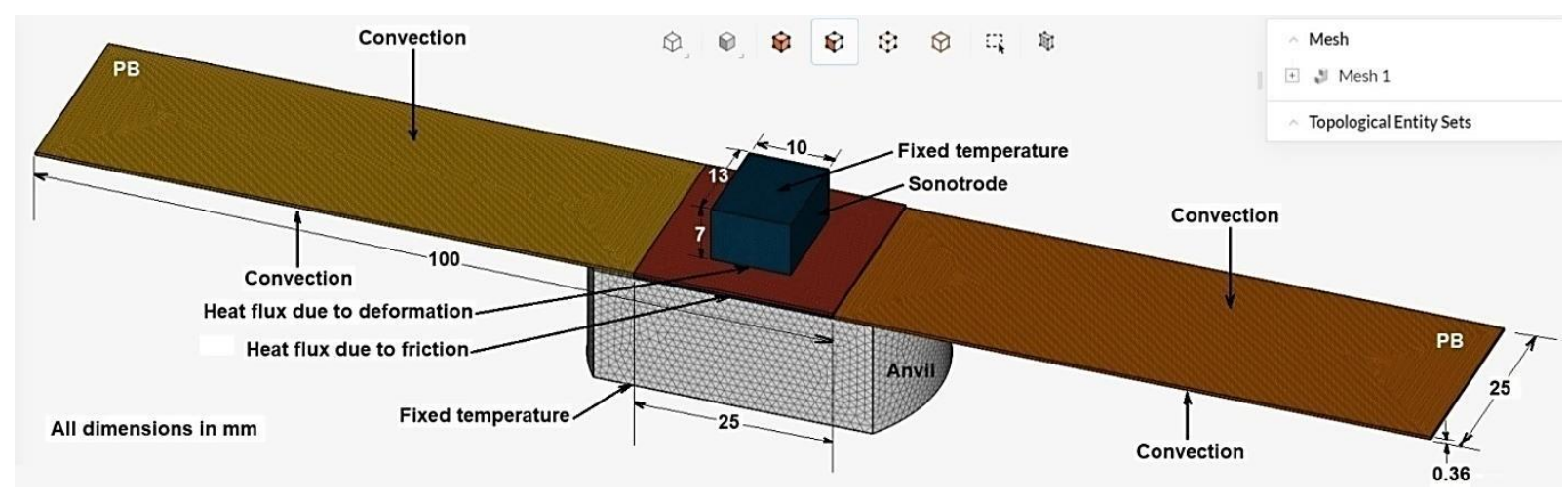

Figure 4. Boundary conditions imposed in the three dimensional FE model of USW

Table 2. Material properties

\begin{tabular}{ccccc}
\hline Property & Unit & $\begin{array}{c}\text { Weld material }- \\
\text { UNS C51100 }\end{array}$ & $\begin{array}{c}\text { Sonotrode Material - } \\
\text { Ti alloy (Ti-6Al-4V) }\end{array}$ & $\begin{array}{c}\text { Anvil Material - } \\
\text { Tool Steel }\end{array}$ \\
\hline Density & $\mathrm{Kg} / \mathrm{m}^{3}$ & 8860 & 4430 & 7670 \\
Young's modulus & $\mathrm{GPa}$ & 110 & 113.8 & 205 \\
Yield Strength & $\mathrm{MPa}$ & 295 (H01 hard) & 880 & - \\
Poisson's ratio & - & 0.34 & 0.34 & 0.30 \\
Thermal conductivity & $\mathrm{W} / \mathrm{m} . \mathrm{K}$ & 84 & 6.7 & 20 \\
Specific heat & $\mathrm{J} / \mathrm{kg} . \mathrm{K}$ & 380 & 526.3 & 460 \\
\hline
\end{tabular}

The heat flux values calculated according to the Eqs. (5) and (6) were applied to the interface only rather than to the entire assembly. It was done according to the work of Jedrasiak [29] who established that in the case of thin metallic deforming sheets, the heat fluxes applied separately to the interface and the bulk, do not affect much to the temperature distribution at the interface. The heat flux produced due to deformation of weld metal was applied uniformly at the 
interface where the sonotrode tip touches the upper weld coupon whereas the heat flux due to friction was applied at the contacting weld interface. The upper surface of the sonotrode tip and the bottom surface of the anvil, both were kept at a fixed temperature of $30^{\circ} \mathrm{C}$ assuming there will be no heat flux across these surfaces in this short weld time. The outer surfaces of the model which were exposed to the air and not in contact with the sonotrode or the anvil were assigned with natural convection having the convective heat transfer coefficient of $5 \mathrm{Wm}^{-2}{ }^{-1}[17]$. The ambient temperature was taken as $30^{\circ} \mathrm{C}$ and the whole model was set at this initial temperature. The simulation was executed in a transient condition taking a time step of $0.1 \mathrm{sec}$.

\section{RESULTS AND DISCUSSION}

The thermal simulation study of the CAD model of USW of phosphor bronze sheets was performed, and the prediction results are tabulated along with the experimentally observed values of the interface temperature in Table 3. All precautions were taken during temperature measurement, despite that some results were found inconsistent due to extremely fast processing time, the possibility of thermocouple deformation and vibration at the point of measurement. The effect of tremendous vibrations on the temperature profile was visible in the enlarged view, where the temperature values are fluctuating in the range of $10-15^{\circ} \mathrm{C}$ for a period of about 0.011 seconds as shown in Figure 5 . Therefore, the measurements were repeated until the reliable results were obtained and only those temperature profiles were accepted which have similar heating and cooling histories without any abnormal fall or quick rise.

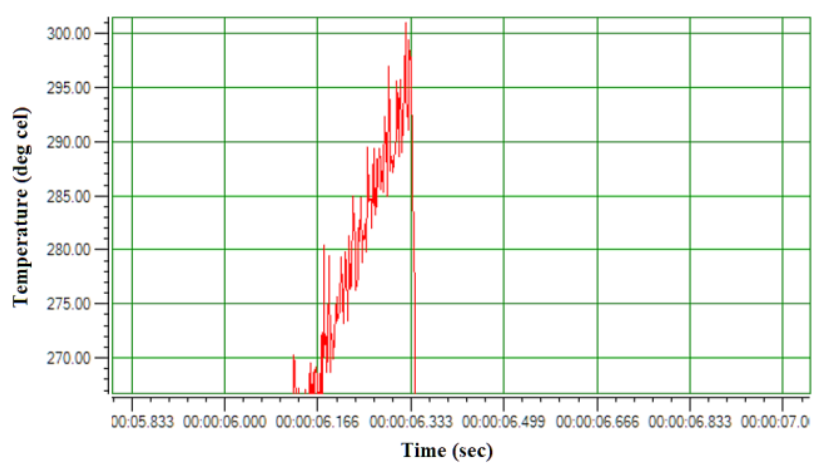

Figure 5. Fluctuation of temperature due to vibration during ultrasonic welding

Table 3. Experimental and simulation temperature data

\begin{tabular}{|c|c|c|c|c|c|c|c|c|c|c|c|}
\hline \multirow[t]{2}{*}{$\begin{array}{l}\text { Run } \\
\text { No. }\end{array}$} & \multirow{2}{*}{$\begin{array}{l}\text { Clamp- } \\
\text { ing } \\
\text { Force } \\
(\mathrm{N})\end{array}$} & \multirow{2}{*}{$\begin{array}{l}\text { Sonotrode } \\
\text { Amplitude } \\
\quad(\mu \mathrm{m})\end{array}$} & \multirow{2}{*}{$\begin{array}{l}\text { Weld } \\
\text { Time } \\
\text { (sec) }\end{array}$} & \multirow{2}{*}{$\begin{array}{c}\text { Weld } \\
\text { Area } \\
\left(\mathbf{m m}^{2}\right)\end{array}$} & \multirow{2}{*}{$\begin{array}{l}\text { Bond- } \\
\text { ing } \\
\text { ratio } \\
(\boldsymbol{\beta})\end{array}$} & \multirow{2}{*}{$\begin{array}{c}\text { Simulation } \\
\text { Tempera- } \\
\text { ture data } \\
\left({ }^{\circ} \mathrm{C}\right)\end{array}$} & \multicolumn{3}{|c|}{$\begin{array}{c}\text { Experimental } \\
\text { Temperature data }\left({ }^{\circ} \mathrm{C}\right)\end{array}$} & \multirow{2}{*}{$\begin{array}{c}\text { Average } \\
\text { Tempera- } \\
\text { ture } \\
\left({ }^{\circ} \mathrm{C}\right)\end{array}$} & \multirow{2}{*}{$\begin{array}{c}\text { Tensile- } \\
\text { shear } \\
\text { load* } \\
(\mathbf{N})\end{array}$} \\
\hline & & & & & & & Trial 1 & Trial 2 & Trial 3 & & \\
\hline 1 & 1650 & 28.0 & 1.20 & 65.40 & 0.42 & 321.3 & 329.7 & 292.6 & 319.4 & 313.9 & 1580.00 \\
\hline 2 & 1650 & 31.5 & 0.85 & 51.30 & 0.50 & 315.0 & 301.0 & 327.1 & 315.1 & 314.4 & 1781.67 \\
\hline 3 & 2200 & 28.0 & 0.85 & 71.58 & 0.39 & 294.0 & 293.9 & 299.1 & 300.0 & 297.7 & 1226.67 \\
\hline 4 & 1100 & 31.5 & 0.50 & 41.25 & 0.43 & 244.0 & 239.3 & 258.3 & 223.6 & 240.4 & 603.00 \\
\hline 5 & 1100 & 28.0 & 0.85 & 33.78 & 0.26 & 250.5 & 255.9 & 263.8 & 243.7 & 254.5 & 703.67 \\
\hline 6 & 1650 & 35.0 & 1.20 & 56.40 & 0.57 & 351.7 & 345.6 & 335.2 & 340.6 & 340.5 & 2306.67 \\
\hline 7 & 1650 & 35.0 & 0.50 & 55.00 & 0.38 & 287.2 & 295.3 & 308.2 & 295.4 & 299.6 & 1246.67 \\
\hline 8 & 1100 & 35.0 & 0.85 & 74.33 & 0.45 & 276.9 & 293.5 & 275.2 & 270.2 & 279.6 & 738.33 \\
\hline 9 & 1650 & 28.0 & 0.50 & 59.08 & 0.32 & 281.0 & 290.0 & 294.9 & 283.5 & 289.5 & 1216.00 \\
\hline 10 & 2200 & 35.0 & 0.85 & 76.48 & 0.65 & 366.7 & 370.7 & 332.6 & 361.0 & 354.7 & 2353.33 \\
\hline
\end{tabular}


Table 3. Experimental and simulation temperature data (cont.)

\begin{tabular}{|c|c|c|c|c|c|c|c|c|c|c|c|}
\hline \multirow[t]{2}{*}{$\begin{array}{l}\text { Run } \\
\text { No. }\end{array}$} & \multirow{2}{*}{$\begin{array}{l}\text { Clamp- } \\
\text { ing } \\
\text { Force } \\
(\mathbf{N})\end{array}$} & \multirow{2}{*}{$\begin{array}{c}\text { Sonotrode } \\
\text { Amplitude } \\
\quad(\mu \mathrm{m})\end{array}$} & \multirow{2}{*}{$\begin{array}{l}\text { Weld } \\
\text { Time } \\
\text { (sec) }\end{array}$} & \multirow{2}{*}{$\begin{array}{l}\text { Weld } \\
\text { Area } \\
\left(\mathbf{m m}^{2}\right)\end{array}$} & \multirow{2}{*}{$\begin{array}{l}\text { Bond- } \\
\text { ing } \\
\text { ratio } \\
(\beta)\end{array}$} & \multirow{2}{*}{$\begin{array}{c}\text { Simulation } \\
\text { Tempera- } \\
\text { ture data } \\
\left({ }^{\circ} \mathrm{C}\right)\end{array}$} & \multicolumn{3}{|c|}{$\begin{array}{c}\text { Experimental } \\
\text { Temperature data }\left({ }^{\circ} \mathrm{C}\right)\end{array}$} & \multirow{2}{*}{$\begin{array}{c}\text { Average } \\
\text { Tempera- } \\
\text { ture } \\
\left({ }^{\circ} \mathrm{C}\right)\end{array}$} & \multirow{2}{*}{$\begin{array}{c}\text { Tensile- } \\
\text { shear } \\
\text { load* } \\
(\mathbf{N})\end{array}$} \\
\hline & & & & & & & Trial 1 & Trial 2 & Trial 3 & & \\
\hline 11 & 2200 & 31.5 & 1.20 & 84.88 & 0.59 & 346.4 & .5 & 330.8 & 346.8 & 349.4 & 2306.67 \\
\hline 12 & 16 & 31.5 & 0. & 49 & 0.5 & 311.3 & 316 & 8 & 7 & 319.5 & 33 \\
\hline 13 & 2200 & 31.5 & 0.50 & 63.40 & 0.39 & 311.9 & 29 & 3 & 31 & 301.6 & 139 \\
\hline 14 & 1650 & 31.5 & 0.85 & 50.85 & 0.49 & 305.5 & 318.9 & 315.7 & 304.1 & 312.9 & 1666.67 \\
\hline 15 & 1100 & 31.5 & 1.20 & 45.05 & 0.35 & 295.7 & 293.1 & 280.2 & 293.4 & 288.9 & 1196.67 \\
\hline
\end{tabular}

* The mean of three experimental trials.

The first simulation trial was performed at run number 5 which has the smallest value of bonding ratio $(\beta=0.26)$ with clamping force $1100 \mathrm{~N}$, sonotrode amplitude of $28.0 \mu \mathrm{m}$ and, weld time $0.85 \mathrm{sec}$. The values of two process parameters, the clamping force and sonotrode amplitude were assigned at a low level in that run. The heat flux values $\mathrm{H}_{\mathrm{d}}$ and $\mathrm{H}_{\mathrm{f}}$ were $85.87 \times 10^{6} \mathrm{~W} / \mathrm{m}^{2}$ and $16.11 \times 10^{6} \mathrm{~W} / \mathrm{m}^{2}$ respectively. The simulation trial performed with those inputs returned the temperature of $250.5^{\circ} \mathrm{C}$. The value of the peak average interface temperature obtained by the thermocouple at the same parameter settings was $254.5^{\circ} \mathrm{C}$. With those parameter settings, the tensile-shear load was obtained as 703.67 $\mathrm{N}$. The values of interface temperature and load are towards the lowest side at the low level of parameters and bonding ratio. The corresponding results from real-time observation and simulation are shown in Figure 6. The temperature distribution is shown along the longitudinal section (x-axis) of the assembly.

The second simulation trial was performed at run number 14 which has the moderate value of bonding ratio $(\beta=$ 0.49 ) with clamping force $1650 \mathrm{~N}$, sonotrode amplitude of $31.5 \mu \mathrm{m}$, and weld time $0.85 \mathrm{sec}$. The values of all the process parameters were assigned at the middle level in that run. The heat flux values $\mathrm{H}_{\mathrm{d}}$ and $\mathrm{H}_{\mathrm{f}}$ were $181.96 \times 10^{6} \mathrm{~W} / \mathrm{m}^{2}$ and $27.19 \times 10^{6} \mathrm{~W} / \mathrm{m}^{2}$ respectively. The simulation trial performed at these inputs returned the temperature of $305.5^{\circ} \mathrm{C}$. The value of the peak average interface temperature obtained by the thermocouple at the same parameter settings was $312.9^{\circ} \mathrm{C}$. The tensile-shear load obtained at this parameter setting was $1666.67 \mathrm{~N}$. The values of interface temperature and load value are higher than the previous simulation run. The corresponding results from real-time observation and simulation are shown in Figure 7. The temperature distribution is shown along the longitudinal section of the assembly.

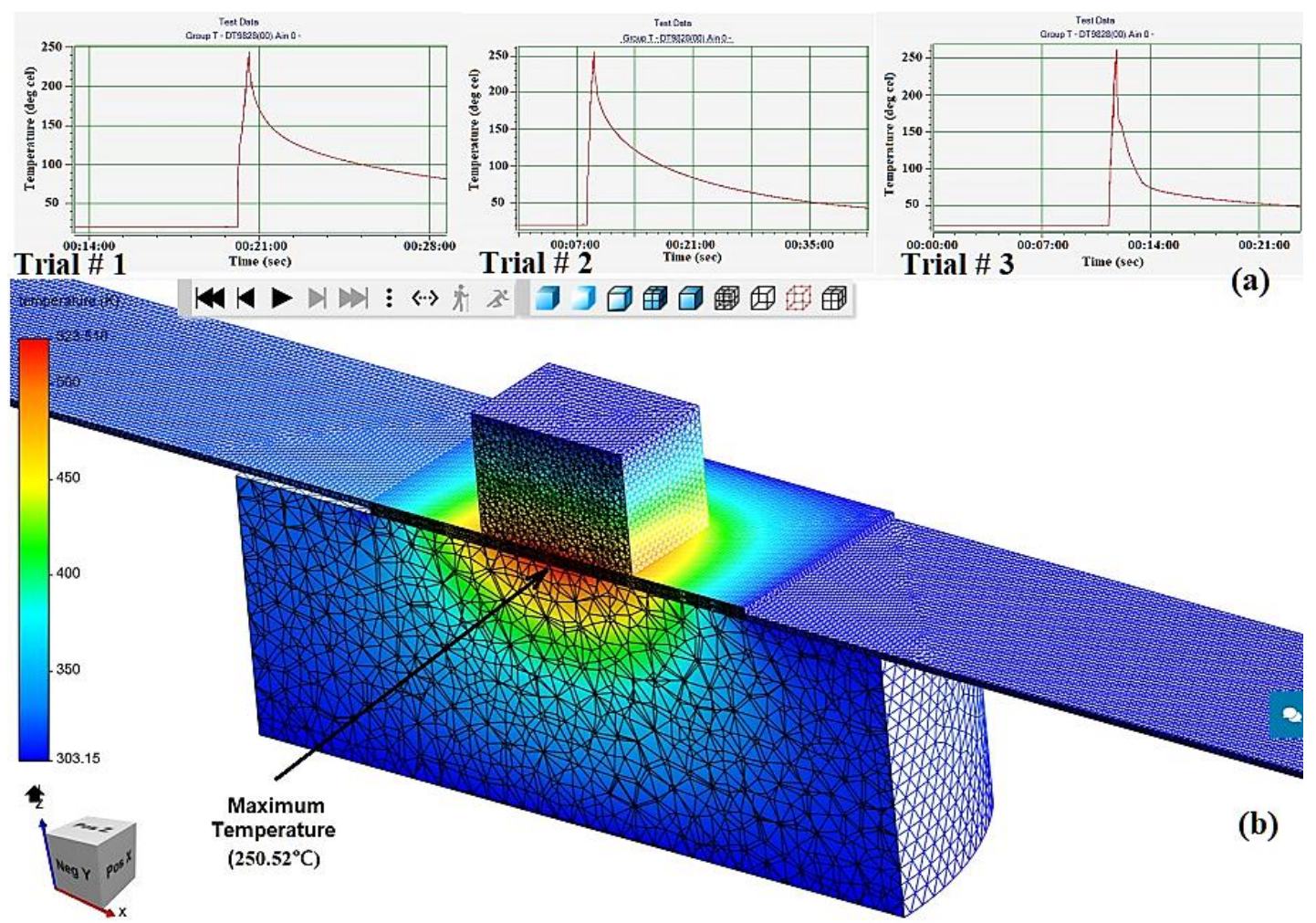

Figure 6. (a) Temperature profile of experimental results and (b) simulation result of run 5 
The third simulation trial was performed at run number 10 which has the highest value of bonding ratio $(\beta=0.65)$ with clamping force $2200 \mathrm{~N}$, sonotrode amplitude of $35.0 \mu \mathrm{m}$, and weld time $0.85 \mathrm{sec}$. The values of two process parameters, the clamping force and sonotrode amplitude were also assigned at a high level in that run. The heat flux values $\mathrm{H}_{\mathrm{d}}$ and $\mathrm{H}_{\mathrm{f}}$ were $268.01 \times 10^{6} \mathrm{~W} / \mathrm{m}^{2}$ and $40.28 \times 10^{6} \mathrm{~W} / \mathrm{m}^{2}$ respectively. The simulation trial performed with those inputs returned the temperature of $366.7^{\circ} \mathrm{C}$. The value of the peak average interface temperature obtained by the thermocouple at the same parameter settings was $354.7^{\circ} \mathrm{C}$. The tensile-shear load obtained at that parameter setting was $2353.33 \mathrm{~N}$. The values of interface temperature and load are the highest at the high level of parameters and bonding ratio. The corresponding results from real-time observation and simulation are shown in Figure 8. The temperature distribution is shown along the longitudinal section of the assembly.

Further, it was observed from the simulated results that the interface temperature increased with the increased clamping force while keeping the sonotrode amplitude and weld time constant. Run 5 and run 3 were simulated at a low level, $28.0 \mu \mathrm{m}$ of sonotrode amplitude. Keeping the weld time fixed at $0.85 \mathrm{sec}$, the simulated results of interface temperature and the value of tensile-shear load increased from $250.5^{\circ} \mathrm{C}$ to $294.0^{\circ} \mathrm{C}$ and $703.67 \mathrm{~N}$ to $1226.67 \mathrm{~N}$ respectively, when the clamping force was increased from $1100 \mathrm{~N}$ to $2200 \mathrm{~N}$. Run 4 and run 13 were simulated at the middle level of sonotrode amplitude at $31.5 \mu \mathrm{m}$ and fixed value of weld time at $0.5 \mathrm{sec}$. The interface temperature and the tensile-shear load increased from $244^{\circ} \mathrm{C}$ to $311.9^{\circ} \mathrm{C}$ and from $603 \mathrm{~N}$ to $1396.67 \mathrm{~N}$ respectively, when the clamping force was increased from $1100 \mathrm{~N}$ to $2200 \mathrm{~N}$. Similarly, high level $35.0 \mu \mathrm{m}$ of sonotrode amplitude and fixed value of weld time at 0.85 sec. were used for simulating run 8 and run 10 . The interface temperature increased from $276.8^{\circ} \mathrm{C}$ to $366.7^{\circ} \mathrm{C}$, while the tensileshear load was increased from $738.33 \mathrm{~N}$ to $2553.33 \mathrm{~N}$ when the clamping force was increased from $1100 \mathrm{~N}$ to $2200 \mathrm{~N}$.

It is also evident from the observation that the interface temperature increases with the increasing value of bonding ratio as shown in Figure 9 (a). The mean values of interface temperatures for a particular set of levels also increased with the mean value of bonding ratios for that particular set of level data as shown in Figure 9 (b).

The bonding ratio represents the part of the area under sonotrode tip which converts into the actual weld area. If the value of the bonding ratio is on the higher side, it implies that more deformable area will be available for the heat flux due to deformation. A parallel relative motion is produced in the contacting surfaces due to the simultaneous action of the ultrasonic vibration. The higher value of clamping force brings the contacting surfaces in close contact with each other, thereby, providing more area for action. As a result, heat generation at the overlapped areas increases which reduces the resistive strength of the oxide and other contaminants against the progressive plastic deformation as well as shearing of the surface asperities. Ultimately, the nascent metallic surfaces start forming micro-welds. The experimental results also corroborate the simulated results.

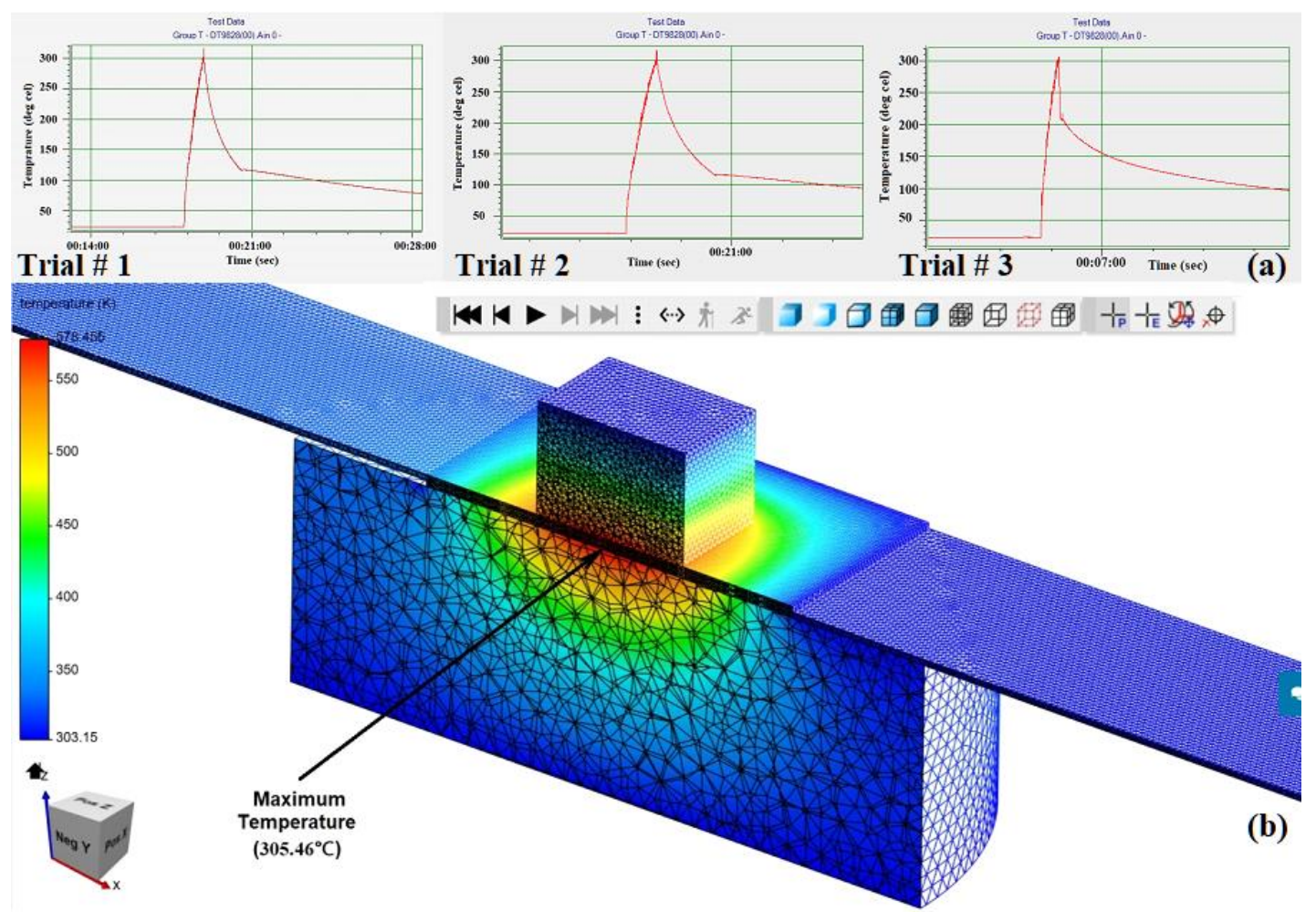

Figure 7. (a) Temperature profile of experimental results and (b) simulation result of run 14 


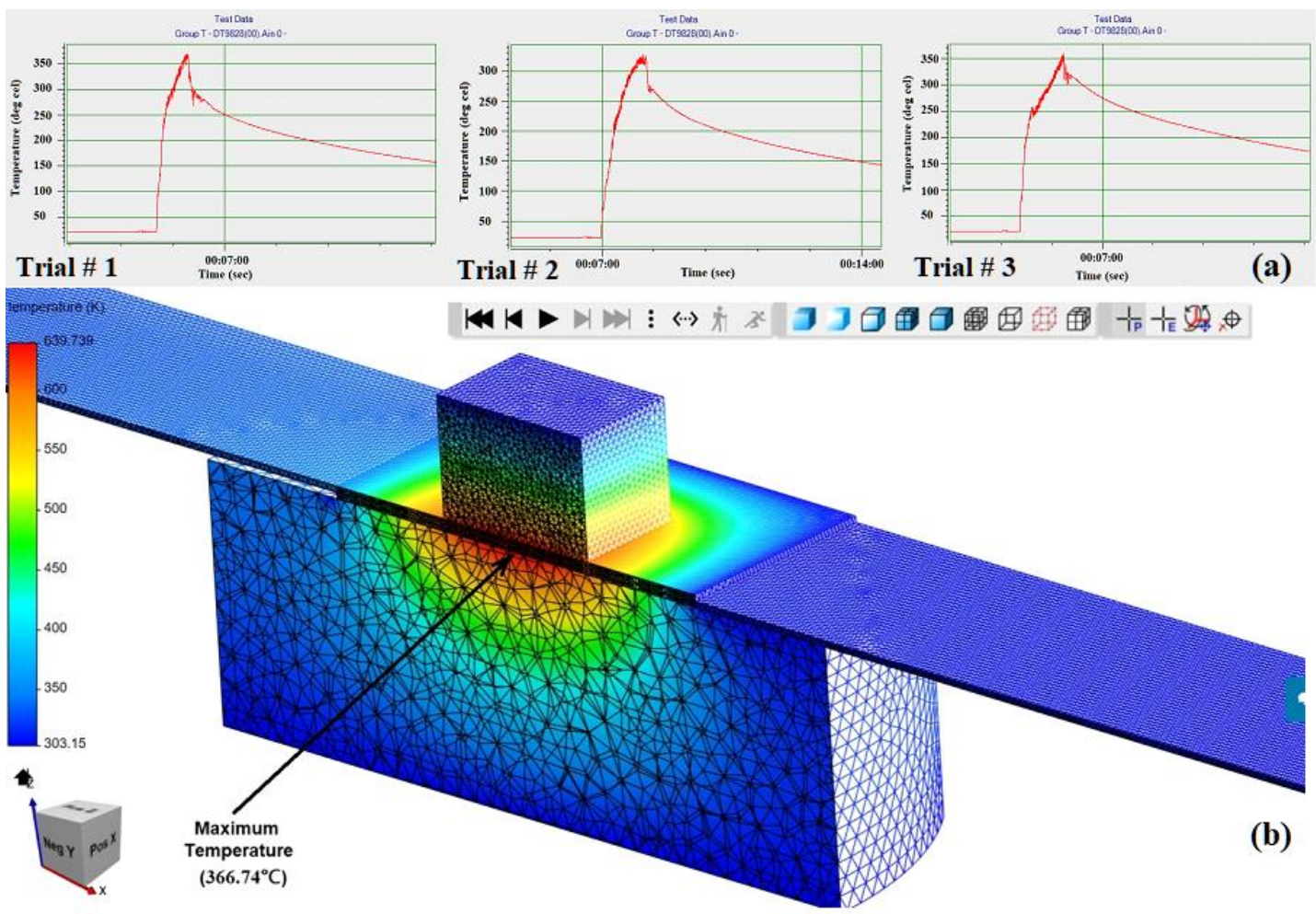

Figure 8. (a) Temperature profile of experimental results and (b) simulation result of run 10
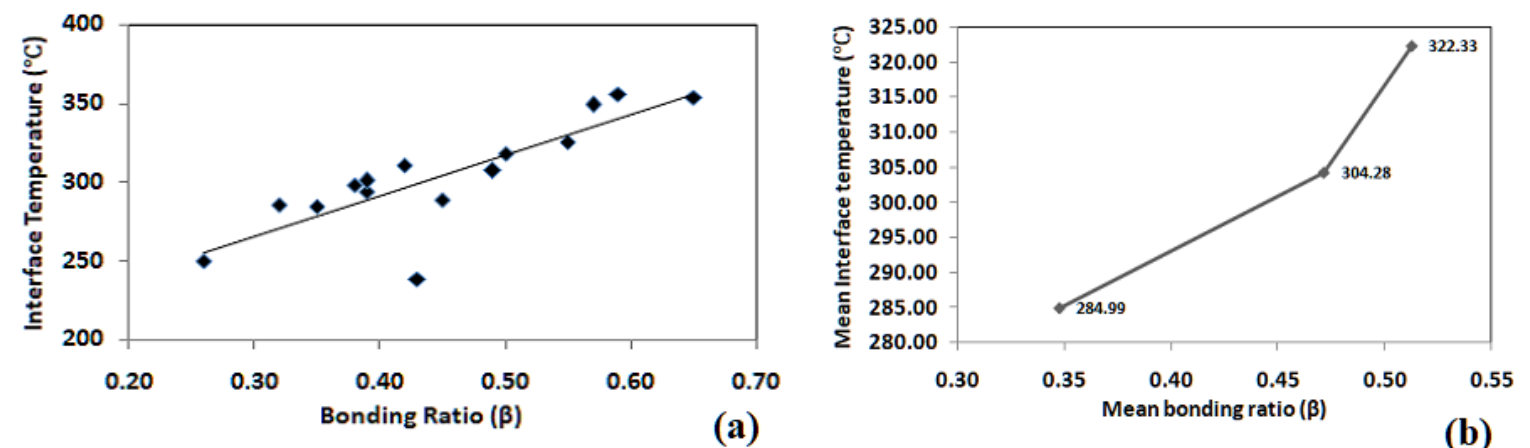

Figure 9. Effect of bonding ration on simulated results of interface temperature: (a) increasing trend in all the simulated runs and (b) increasing trend of mean interface temperature from low level to high level of parameters

\section{Prediction of Thermal Profile in Weld Zone}

The thermal analysis of the USW process can be utilized to predict the temperature at different zones in the weld interface as well as in different parts of the assembly such as sonotrode and anvil. Run number 10 having the highest temperature value and joint strength has been used for prediction analysis. Figure 10 shows the uniformly distributed temperature zones in the upper sheet, lower sheet, sonotrode tip, and anvil. 


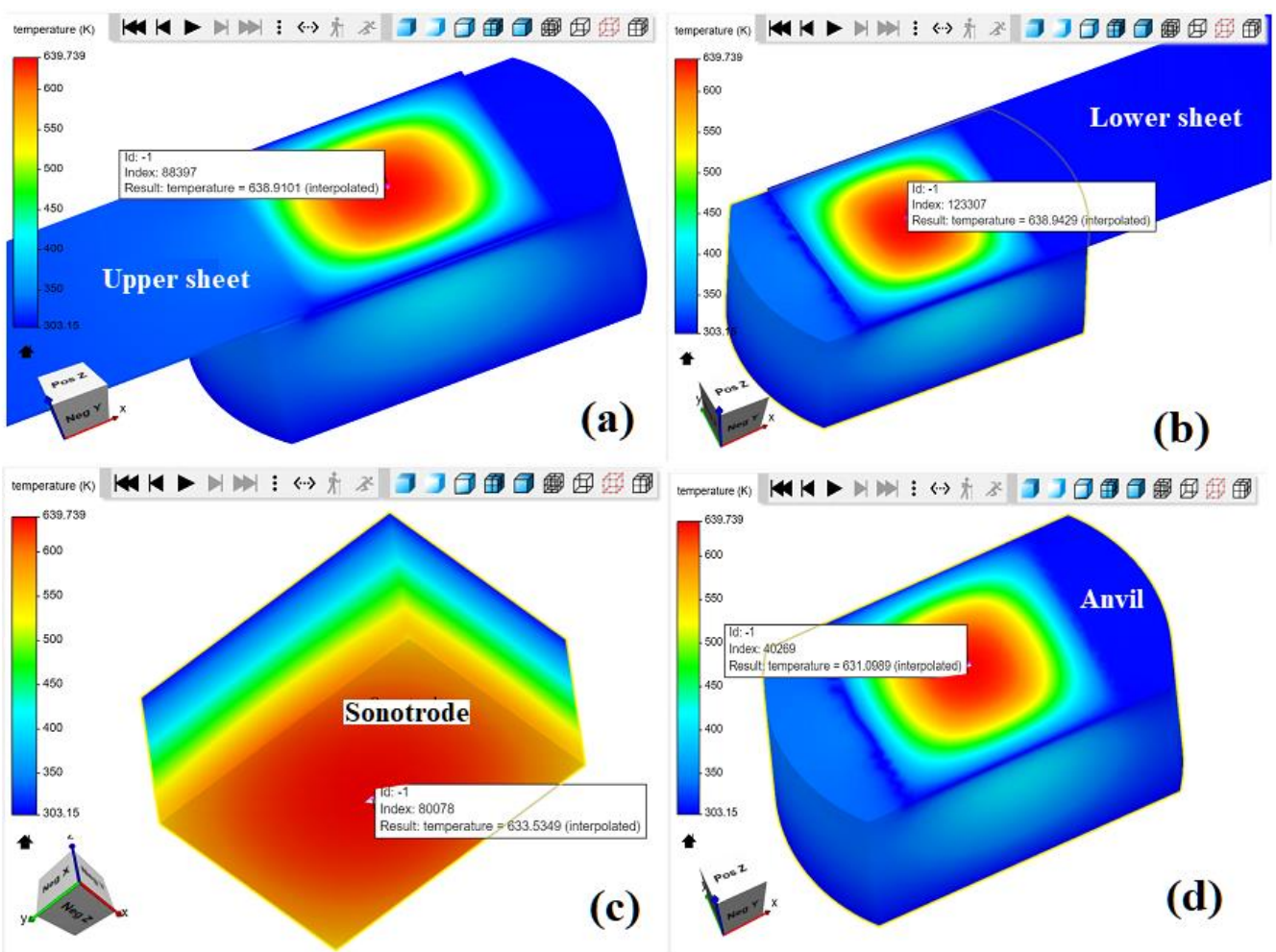

Figure 10. Temperature contour profile in: (a) upper sheet, (b) lower sheet and (c) sonotrode tip and (d) anvil

The temperature at the centre of the zone is also shown. The red colour zones indicated the highest temperature near the weld zone which gradually changed to blue colour away from it indicating the lowest temperature zone. The value of peak temperature in this zone is $366.7^{\circ} \mathrm{C}$. This is a sufficiently high temperature to mobilize the considerable interface activities. Besides, significant plastic deformation having taken place, the oxides layer also gets burst and pure metallic adhesion takes place [30]. The highest temperature is experienced by the area under the sonotrode tip as shown in Figure 10 (a) and (b). Therefore, the top part and the interface of both the sheets go through severe plastic deformation, and the material starts yielding. The surrounding areas, however, are not susceptible to much yielding as is evident from the blue colour of the weld metal sheets. The temperatures towards the extremes of sonotrode and anvil are very less as compared to the weld zone due to their low thermal conductivity as well as low contact thermal conductance relative to the weld material at contacting surfaces. But the surfaces of the sonotrode, and the anvil which come into contact with the parent metal get instantaneous heat, and the temperature at the centre of these surfaces reaches at $360.7^{\circ} \mathrm{C}$ and $357.3^{\circ} \mathrm{C}$ respectively as shown in Figure 10 (c) and (d).

\section{Estimation of TMAZ and HAZ}

These temperature predictions corroborate the existence of TMAZ and HAZ in the vicinity of the weld zone. To explore further thermal activities, the temperatures at the end of the weld cycle at the weld zone were observed. Figure 11 shows the variation of the temperature at the weld interface starting from the centre line below the sonotrode tip and in its surroundings. There is a continuous variation in the colour of the interface both in $\mathrm{X}$ and $\mathrm{Y}$ directions ranging from the hottest (red colour) to the coolest (blue colour) temperature. The central part has maximum temperature where the effects of clamping force and ultrasonic vibrations are concentrated. The interface in this region undergoes severe plastic deformation and heat generation due to friction, thus, has the highest temperature. The oxide layer breaks and asperities reduce in this region to bring nascent metals to come in close contact to initiate micro-bonding. 


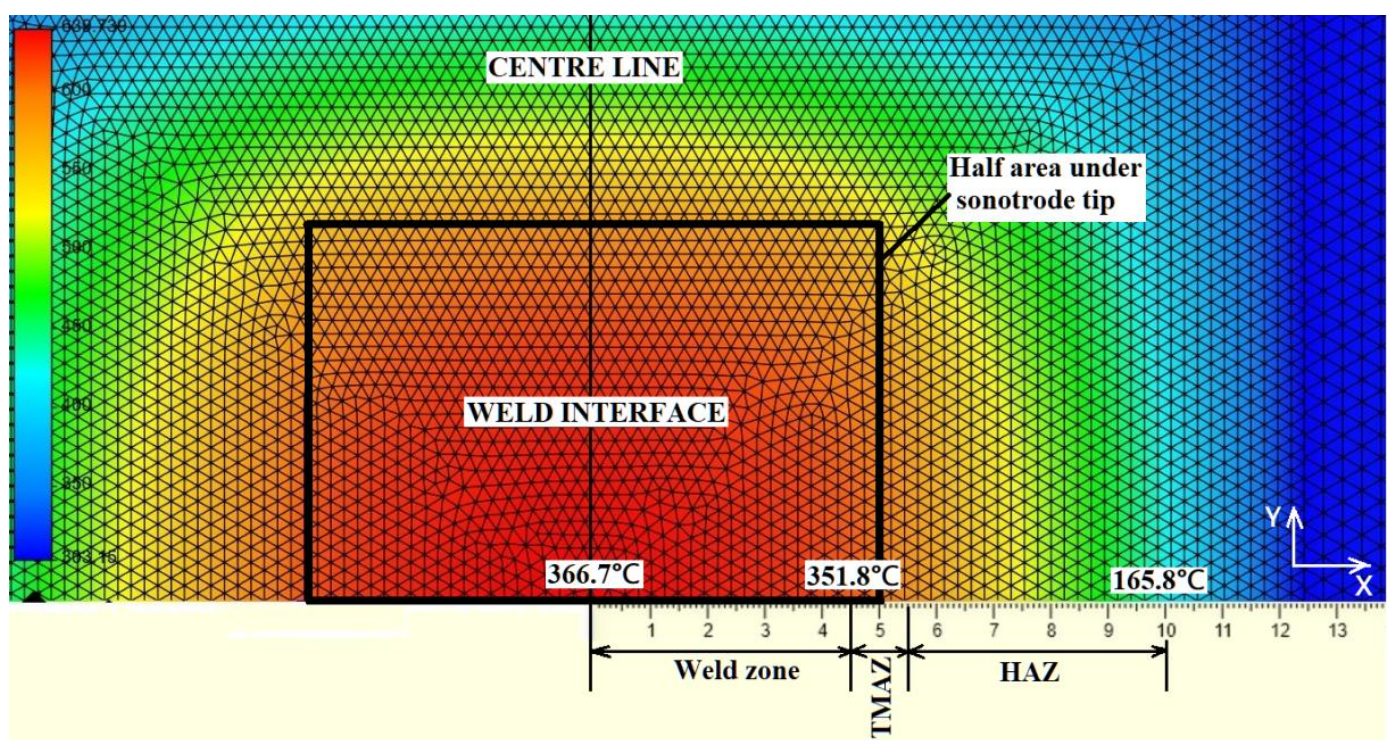

Figure 11. Temperature variation in weld interface along $X$ axis

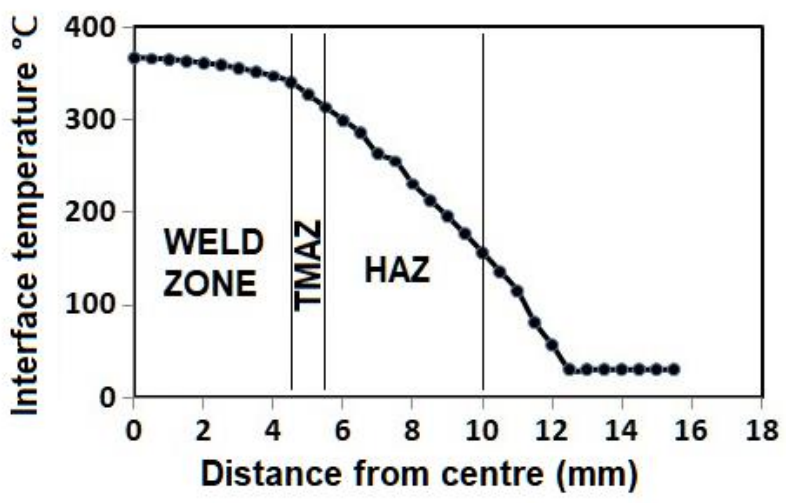

Figure 12. Different zones in weld interface

Plotting the interface temperature along the X-axis with respect to the distance from the centre (Figure 12) reveals more interesting information. It is observed that the maximum interface temperature at the end of the weld cycle is almost constant up to a certain distance along $\mathrm{X}$-axis. The temperature at the centre line is $366.7^{\circ} \mathrm{C}$ which decreases to $351.8^{\circ} \mathrm{C}$ at $4.5 \mathrm{~mm}$ from centre line under sonotrode tip. It is the area that experiences severe plastic deformation. The microbonding initiates in this region. This area is known as the 'deformation zone' or 'weld zone'. There is a sharp fall in the temperature afterward. For about $1 \mathrm{~mm}$, the temperature falls from $340.4^{\circ} \mathrm{C}$ to $318.0^{\circ} \mathrm{C}$. This zone also experiences metal softening due to plastic deformation and frictional heat. This is called the 'friction zone' and may be considered as TMAZ. It spreads beyond the boundary of the sonotrode tip. The recrystallization temperature is usually 0.3 to 0.6 times the melting temperature [24]. The temperature in TMAZ is within this range. The temperature continues to fall further and reaches $165.8^{\circ} \mathrm{C}$ at a $10 \mathrm{~mm}$ distance from the centre. This is the 'non-contact zone' where no bonding takes place but some microstructural changes may be observed due to heat. This may be treated as HAZ. The boundary of the green colour in Figure 10 represents the end of HAZ.

Similarly, Figure 13 shows the thermal profile of sonotrode in an upward direction at the end of weld time. The colour distribution corresponding to the temperature varies from hottest (red colour, $352.42^{\circ} \mathrm{C}$ ) at the bottom to the coolest (blue colour, $30.15^{\circ} \mathrm{C}$ ) at the top within a height of $7 \mathrm{~mm}$. It is obvious that the span of TMAZ is nil and HAZ is spread in a very small area in comparison to the weld metal. Very low thermal conductivity of sonotrode material and exposure of all the surfaces except one to the atmospheric air is responsible for this effect. The temperature variation of the sonotrode tip along the $\mathrm{Y}$-axis is plotted in Figure 14. The temperature consistently decreased while moving upward from the bottom of the sonotrode with a temperature gradient of $46^{\circ} \mathrm{C} / \mathrm{mm}$. Reduced heat loss from the sonotrode helps in retaining more heat at the interface so that interface is able to attain a higher value of maximum temperature. 


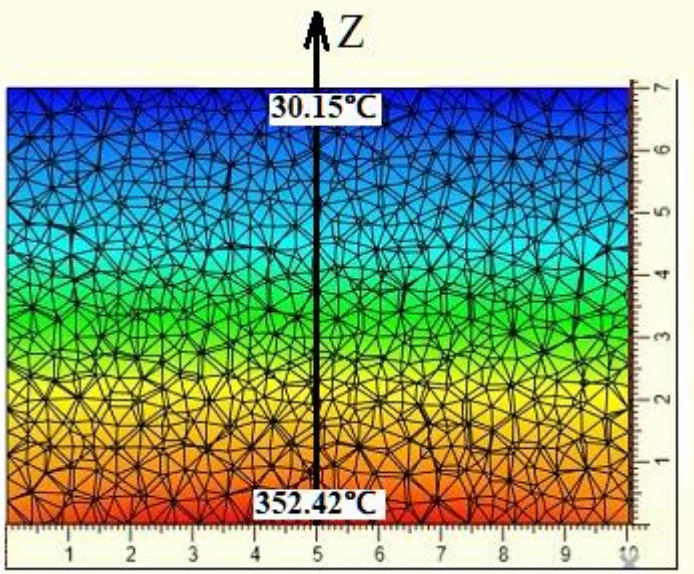

Figure 13. Temperature variation in sonotrode along $\mathrm{Z}$ axis

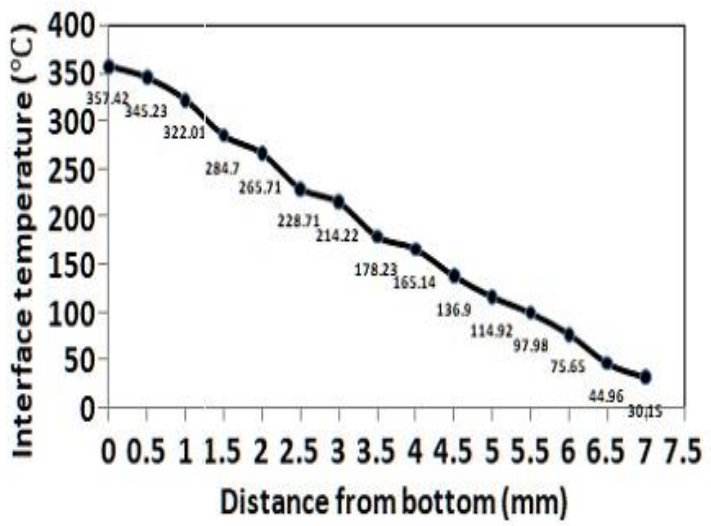

Figure 14. Plot between sonotrode temperature and distance along $\mathrm{Z}$ axis

\section{Model Validation}

A model is considered efficient if it gives comparable results. The temperature values measured by the thermocouple and those obtained by the simulation were compared and plotted in Figure 15. Both the results are in good agreement with each other with the maximum absolute error of $1.576 \%$. It reflects that the developed FEA model can be efficiently utilized to predict the interface temperature and the boundary conditions presumed in the model may be treated as valid.

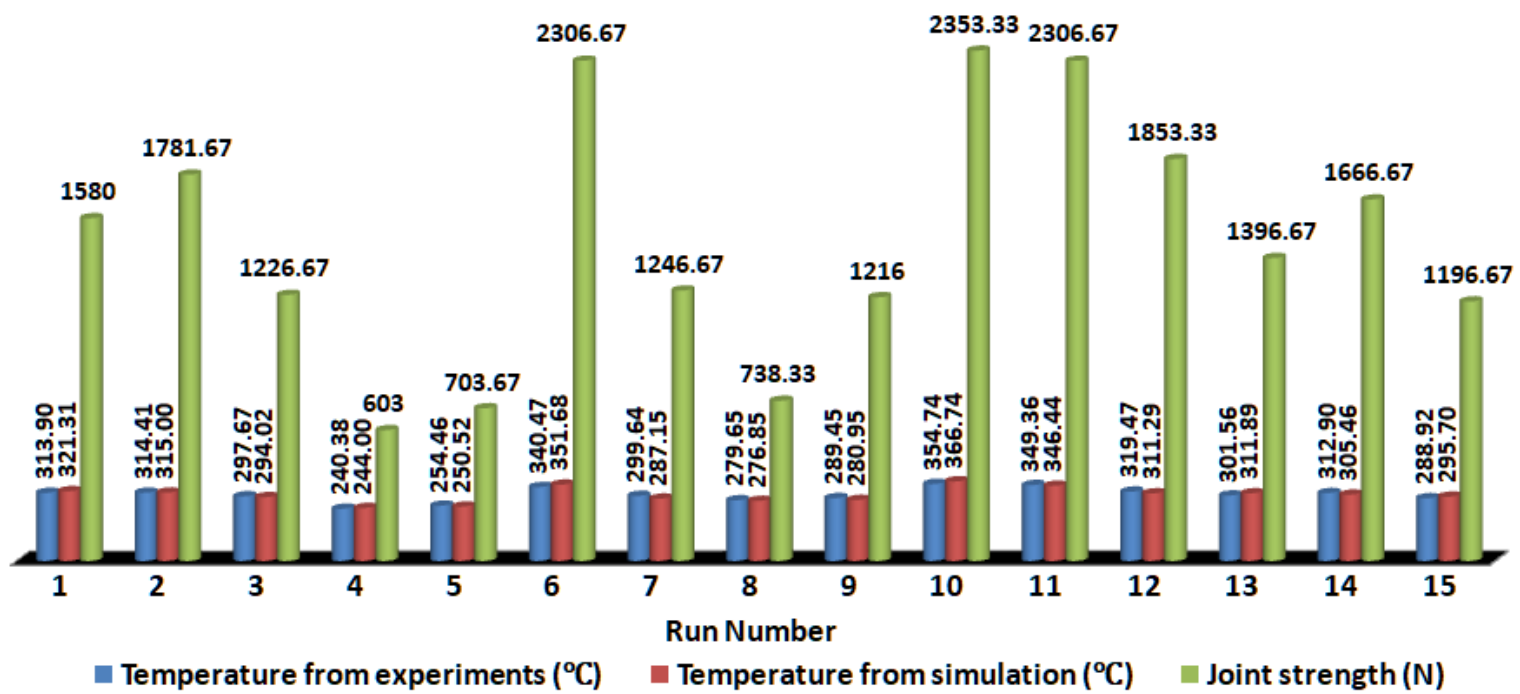

Figure 15. Comparison of interface temperature with joint strength

The ultimate tensile-shear load which is an indicative of the joint strength of the welded coupons was measured by pulling the joined weld coupons using UTM at a controlled specified speed. The optimal solution to achieve maximum joint strength was obtained at weld time $=1.2 \mathrm{sec}$, weld pressure $=0.36 \mathrm{MPa}$ and vibration amplitude $=35 \mu \mathrm{m}$ using Design-Expert software. The confirmatory tests performed at optimized parameter values resulted in the mean ultimate load of $2862.8 \mathrm{~N}$ which is about $74 \%$ of the strength of the base metal. Figure 12 also shows the joint strength along with the interface temperature. A correlation coefficient of 0.96 was calculated between interface temperature obtained by simulation and the joint strength to confirm their linear association. This value proves a strong correlation between the temperature developed at the interface and the weld strength. It signifies that the interface temperature may be considered to be an indicator of weld strength, and its value plays an important role in achieving stronger joints.

\section{CONCLUSIONS}

The finite element analysis of a 3-D model of USW is accomplished, and the model is utilized to predict the interface temperature. The following conclusions can be recapitulated:

i. The thermal model of the ultrasonically welded phosphor bronze sheets can effectively forecast the temperature results under various welding conditions. The peak temperature observed at the weld interface through 
simulation is nearly $1 / 3^{\text {rd }}$ of the melting point of phosphor bronze, hence, it is ascertained that USW is a solidstate joining technique.

ii. The maximum temperature observed at the centre of the weld interface is $366.74^{\circ} \mathrm{C}$ which diminishes continuously towards the extremes of the weld strips. Owing to the lower thermal conductivity of sonotrode material the maximum temperature obtained by it was lower in comparison to the maximum temperature of the weld interface.

iii. Clamping force and bonding ratio directly influence the interface temperature. Higher values of both the parameters produce a higher temperature.

iv. The three zones observed at the interface are weld zone, TMAZ, and HAZ. The TMAZ spreads up to $1 \mathrm{~mm}$ after the weld zone is finished and acted upon by severe acoustic softening. The HAZ is observed further up to $4.5 \mathrm{~mm}$.

v. The model is validated with an error of $1.576 \%$ between the observed and predicted temperature results. Hence, the boundary conditions presumed in this model may be considered justified. A correlation coefficient of 0.96 established between the simulated temperature values, and the weld strength proves a strong linear relationship between them. Sufficiently strong joints were obtained at the optimum welding conditions with $74 \%$ joint efficiency.

\section{Disclosure Statement}

No potential conflict of interests was reported by the authors.

\section{REFERENCES}

[1] J. Yang and B. Cao, "Investigation of resistance heat assisted ultrasonic welding of 6061 aluminum alloys to pure copper," Mater. Des., vol. 74, pp. 19-24, 2015, doi: 10.1016/j.matdes.2015.02.028.

[2] A. Das, "Joining Technologies for Automotive Battery Systems Manufacturing," World Electr. Veh. J., vol. 9, no. 22, pp. 113, 2018, doi: 10.3390/wevj9020022.

[3] B. Mo, Z. Guo, Y. Li, Z. Huang, and G. Wang, "Mechanism of resistance microwelding of insulated copper wire to phosphor bronze sheet," Mater. Trans., vol. 52, no. 6, pp. 1252-1258, 2011, doi: 10.2320/matertrans.M2011013.

[4] M. Weigl, M. Schmidt, E. Govekar, and A. Jeric, "Laser droplet generation : Application to droplet joining," CIRP Ann. Manuf. Technol., vol. 58, pp. 205-208, 2009, doi: 10.1016/j.cirp.2009.03.005.

[5] S. Consiglio, T. Fleschutz, G. Seliger, and J. Seutemann, "Development of a duothermal soldering process," Ann. CIRP, vol. 55 , no. 1, pp. 1-4, 2006.

[6] K. Conway, P. P., Fu, E.K.Y., Williams, "Precision high temperature lead-free solder interconnections by means of high-energy droplet deposition techniques," CIRP Ann., vol. 51, no. 1, pp. 177-180, 2002.

[7] C. Q. Zhang, J. D. Robson, O. Ciuca, and P. B. Prangnell, "Microstructural characterization and mechanical properties of high power ultrasonic spot welded aluminum alloy AA6111-TiAl6V4 dissimilar joints," Mater. Charact., vol. 97, pp. 83-91, 2014, doi: 10.1016/j.matchar.2014.09.001.

[8] R. R. Dehoff and S. S. Babu, "Characterization of interfacial microstructures in 3003 aluminum alloy blocks fabricated by ultrasonic additive manufacturing," Acta Mater., vol. 58, no. 13, pp. 4305-4315, 2010, doi: 10.1016/j.actamat.2010.03.006.

[9] B. Sanga, R. Wattal, and D. S. Nagesh, "Mechanism of joint formation and characteristics of interface in ultrasonic welding: Literature review," Period. Eng. Nat. Sci., vol. 6, no. 1, 2018, doi: 10.21533/pen.v6i1.158.

[10] S. Elangovan, S. Venkateshwaran, and K. Prakasan, "Experimental investigations on optimization of ultrasonic welding parameters for copper to brass joints using response surface method and genetic algorithm," Int. J. Adv. Eng. Res., pp. 55-64, 2012.

[11] D. Zhao, D. Ren, K. Zhao, S. Pan, and X. Guo, "Effect of welding parameters on tensile strength of ultrasonic spot welded joints of aluminum to steel - By experimentation and artificial neural network," J. Manuf. Process., vol. 30, pp. 63-74, 2017, doi: 10.1016/j.jmapro.2017.08.009.

[12] Z. Ni, H. Zhao, P. Mi, and F. Ye, "Microstructure and mechanical performances of ultrasonic spot welded Al/Cu joints with Al 2219 alloy particle interlayer," Mater. Des., vol. 92, pp. 779-786, 2016, doi: 10.1016/j.matdes.2015.12.132.

[13] M. P. Satpathy, S. B. Mishra, and S. K. Sahoo, "Ultrasonic spot welding of aluminum-copper dissimilar metals: A study on joint strength by experimentation and machine learning techniques," J. Manuf. Process., vol. 33, no. April, pp. 96-110, 2018, doi: 10.1016/j.jmapro.2018.04.020.

[14] X. Zhong, J. Feng, and S. Yao, "Temperature field modeling and experimental study on ultrasonic consolidation for Al-Ti foil $\dagger$ †” J. Mech. Sci. Technol., vol. 33, no. 6, pp. 2833-2840, 2019, doi: 10.1007/s12206-019-0530-8.

[15] K. S. Suresh, M. R. Rani, K. Prakasan, and R. Rudramoorthy, "Modeling of temperature distribution in ultrasonic welding of thermoplastics for various joint designs," J. Mater. Process. Technol., vol. 186, no. 1-3, pp. 138-146, 2007, doi: 10.1016/j.jmatprotec.2006.12.028.

[16] E. de Vries, "Mechanics and Mechanisms of Ultrasonic Metal Welding," Ph.D. Thesis, The Ohio State University, 2004. 
[17] S. Elangovan, S. Semeer, and K. Prakasan, "Temperature and stress distribution in ultrasonic metal welding-An FEA-based study,” J. Mater. Process. Technol., vol. 209, no. 3, pp. 1143-1150, 2009, doi: 10.1016/j.jmatprotec.2008.03.032.

[18] E. Sooriyamoorthy, S. P. John Henry, and P. Kalakkath, "Experimental studies on optimization of process parameters and finite element analysis of temperature and stress distribution on joining of $\mathrm{Al}-\mathrm{Al}$ and $\mathrm{Al}-\mathrm{Al} 2 \mathrm{O} 3$ using ultrasonic welding," Int. $J$. Adv. Manuf. Technol., vol. 55, no. 5-8, pp. 631-640, 2010, doi: 10.1007/s00170-010-3059-7.

[19] K. K. Chen and Y. S. Zhang, "Numerical analysis of temperature distribution during ultrasonic welding process for dissimilar automotive alloys," Sci. Technol. Weld. Join., vol. 20, no. 6, pp. 522-531, 2015, doi: 10.1179/1362171815Y.0000000022.

[20] P. Jedrasiak, H. R. Shercliff, Y. C. Chen, L. Wang, P. Prangnell, and J. Robson, "Modeling of the thermal field in dissimilar alloy ultrasonic welding," J. Mater. Eng. Perform., vol. 24, no. 2, pp. 799-807, 2015, doi: 10.1007/s11665-014-1342-8.

[21] P. Jedrasiak and H. R. Shercliff, "Finite element analysis of heat generation in dissimilar alloy ultrasonic welding," Mater. Des., vol. 158, pp. 184-197, 2018, doi: 10.1016/j.matdes.2018.07.041.

[22] U. I. Chang and J. Frisch, "On optimization of some parameters in ultrasonic metal welding," Weld. J., vol. 53, no. 1, pp. 24s36s, 1974.

[23] M. Shakil, N. H. Tariq, M. Ahmad, M. A. Choudhary, J. I. Akhter, and S. S. Babu, "Effect of ultrasonic welding parameters on microstructure and mechanical properties of dissimilar joints," Mater. Des., vol. 55, pp. 263-273, 2014, doi: 10.1016/j.matdes.2013.09.074.

[24] A. K. Bhargava, M. K. Banerjee, and M. National, Chapter 09196 - 2.14 Heat-Treating Copper and Nickel Alloys, vol. 2. Elsevier Ltd., 2017.

[25] M. Winter, "Benchmark and Validation of open source CFD codes, with focus on compressible and rotating capabilities, for integration on the SimScale platform," 2013.

[26] K. Chen and Y. Zhang, "Thermal-mechanical analysis of ultrasonic spot welding considering acoustic softening effect," Procedia Eng., vol. 81, October, pp. 2117-2122, 2014, doi: 10.1016/j.proeng.2014.10.295.

[27] J. R. Davis and D. \& Associates, ASM Specialty Handbook- Copper and copper alloys, 2001st ed. ASM International, Materials Park, OH 44073-0002, 2001.

[28] L. S. Fletcher, "Recent Developments in Contact Conductance Heat Transfer," vol. 110, November 1988, 2013.

[29] P. Jedrasiak et al., "Thermal Modeling of Al-Al and Al-Steel Friction Stir Spot Welding,” J. Mater. Eng. Perform., 32, 2016, doi: 10.1007/s11665-016-2225-y.

[30] D. Bakavos and P. B. Prangnell, "Mechanisms of joint and microstructure formation in high power ultrasonic spot welding 6111 aluminium automotive sheet," Mater. Sci. Eng. A, vol. 527, no. 23, pp. 6320-6334, 2010, doi: 10.1016/j.msea.2010.06.038. 